\title{
'A'ALI'I AND WÁHTA OTERONTONNİ:'A: SYMBOLS OF INDIGENOUS INNOVATION FOR LINGUISTIC AND CULTURAL RESILIENCE
}

\author{
Ryan DeCaire 1 \\ Ka Haka 'Ula o Ke'elikōlani, University of Hawai'i at Hilo; University of Toronto \\ Naupaka Damienne Joaquin \\ Ka Haka 'Ula o Ke'elikōlani, University of Hawai'i at Hilo \\ Nicholas Keali'i Lum \\ Ka Haka 'Ula o Ke'elikōlani, University of Hawai'i at Hilo \\ Ian Nāhulu Maioho \\ Ka Haka 'Ula o Ke'elikōlani, University of Hawai'i at Hilo
}

\begin{abstract}
Like the humble 'a'ali'i shrub growing abundantly throughout the Hawaiian island chain or the gentle wáhta oterontonnì:'a (sugar maple sapling) native to the Haudenosaunee territory in the north-eastern woodlands of North America, both adapting and thriving in different and extreme environments, Indigenous people, amidst foreign pressures to change, are innovating in order to adapt and ensure the survival of their unique languages and cultures. This article examines how Indigenous people, with focus on Hawaiian and Kanien'kehá:ka (Mohawk people), are maintaining linguistic and cultural resilience through innovation, something that Indigenous people have arguably been doing since long before the arrival of colonists to their territories. All authors (three Hawaiian and one Kanien'kehá:ka) of this article are doctoral candidates in the Hawaiian and Indigenous Language and Culture Revitalization program at the University of Hawai'i at Hilo, Ka Haka 'Ula o Ke'elikōlani College of Hawaiian Language.
\end{abstract}

Through autoethnography and personal interviews, this article highlights Indigenous innovation within four areas of practice: Hawaiian translation and interpretation, Hawaiian song and music, Indigenous food sovereignty, and Kanien'kéha (Mohawk language) documentation. For the purposes of this article, Indigenous innovation is summarized as innovation through retrospection, making informed decisions for the future based on the past. This article also brings to light obstacles and possible fears surrounding innovation due to the debate between purism (maintaining traditional knowledge and practice) and innovation (creation for adaptation to modern times). Just as the 'a'ali'i or the wáhta oterontonnì:'a remain firmly rooted yet supple in their branches, allowing them to twist and

\footnotetext{
${ }^{1}$ Correspondence: Ryan DeCaire, Ka Haka 'Ula o Ke'elikōlani, University of Hawai'i at Hilo; University of Toronto, ryan.decaire@utoronto.ca
} 
bend with the ever-changing winds, Indigenous people must follow suit in order to ensure linguistic and cultural resilience.

Keywords: Indigenous innovation, resilience, language and culture revitalization, Hawaiian, Mohawk, Kanien'kéha

Citation: DeCaire, R., Joaquin, N. D., Lum, N. K., \& Maioho, I. N. (2021). 'A'ali'i and wáhta oterontonnì:'a: Symbols of Indigenous innovation for linguistic and cultural resilience. WINHEC: International Journal of Indigenous Education Scholarship, 16(1), pp. 376-410. http://dx.doi.org/10.18357/wj1202120292. Special Issue on Indigenous Language Revitalization: Innovation, Reflection and Future Directions, Guest Co-Editors Drs. Onowa McIvor and Kari A. B. Chew. 


\title{
'A'ali'i and Wáhta Oterontonnì:'a: Symbols of Indigenous Innovation for Linguistic and Cultural Resilience
}

\author{
He 'a'ali'i kūmakani mai au, 'a'ohe makani nāna e kula'i. \\ I am a wind-resisting 'a'ali'i shrub, no gale can push me over. \\ -'Ōlelo No'eau (Native Hawaiian Proverb)
}

The opening saying is a Native Hawaiian proverb used to describe a resilient people. The 'a'ali'i (Dodonaea viscosa) is a humble and partially woody shrub that grows from the subalpine shrubland mountain tops down to the sandy coastal shorelines of Hawai'i's vast geological landscape. Growing on all eight major Hawaiian islands, the evergreen 'a'ali'i thrives in coastal dunes, lava fields, dry-mesic forests, and wet forests and is able to tolerate extreme drought, strong winds, and salt spray (Native Plants Hawai'i, 2009). Its sturdy root system is what holds itself grounded while its adaptable stalk and branches allow it to twist and bend in strong gales without breaking (Pukui, 1983). Due to the resilient nature of 'a'ali' $i$, its enduring wood has been traditionally used by Native Hawaiians for building canoes and houses and also for making weapons and agricultural tools (Native Plants Hawai'i, 2009).

Like the 'a'ali'i, the wáhta oterontonnì:'a, or sugar maple (acer saccharum) sapling has long been a symbol of resilience and strength to the Haudenosaunee. Wáhta oteronntonnì:'a is used to refer to the creator of human beings in the Haudenosaunee creation story, ${ }^{2}$ who, one of two twin boys, creates everything upon the earth. In this story, Wáhta Oteronntonnì:'a, also referred to as "Sapling" or "Tharonhiawá:kon" (he holds the sky), battles over control of the world with his twin brother, Shawíhskara (flint). It is said that Shawíhskara was covered

\footnotetext{
${ }^{2}$ For a detailed account of the Haudenosaunee creation story, see: Hewitt, J. N. B. (1903). Iroquoian cosmology. Twenty-first annual report of the Bureau of American Ethnology, 1899-1890.
} 
in sharp flint since birth. After many battles between them, Wáhta Oterontonnì:'a overcomes his brother, Shawíhskara, giving him the power to decide over the fate of the world that they have created. The wáhta, sugar maple tree, is a deciduous hardwood that grows native to Haudenosaunee territory in the north-eastern woodlands of North America. It is regarded as the leader of all trees, as it is the first tree each year to provide sustenance to human beings in the form of maple sap. The wáhta is also known to grow in a wide variety of soil types, in both sun and shade, as well as not being susceptible to high wind damage. The wáhta is even resilient in highly disturbed environments, such as those impacted by forest fires (Gilman \& Watson, 1993; Payette et al., 2018).

Both the 'a'ali'i and the wáhta oterontonnì:'a serve as metaphors for the resilient nature of Indigenous people who remain strong, flexible, and rooted while standing firm in the winds of change by adapting through innovation (see Figure 1 and Figure 2). As true observers and descendants of people who are mindful of nature's occurrences, Indigenous researchers demonstrate that prolific connections of environmental elements are complemented by academic research within Native frameworks. 


\section{Figure 1}

Illustration of the 'A'ali'i as Metaphor for Indigenous Resilience by Ian Nāhulu Maioho

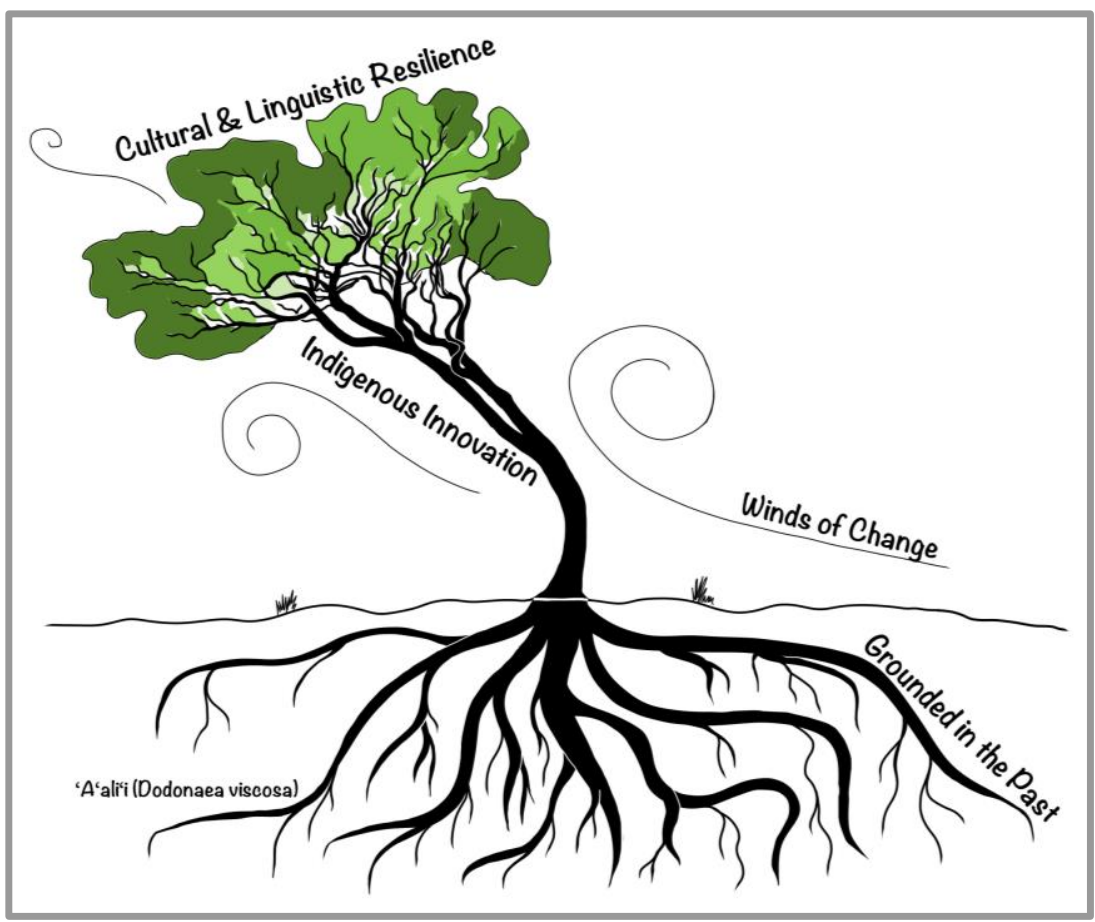




\section{Figure 2}

Illustration of the Wáhta Oterontonnì:'a as Metaphor for Indigenous Resilience by Ian Nāhulu Maioho

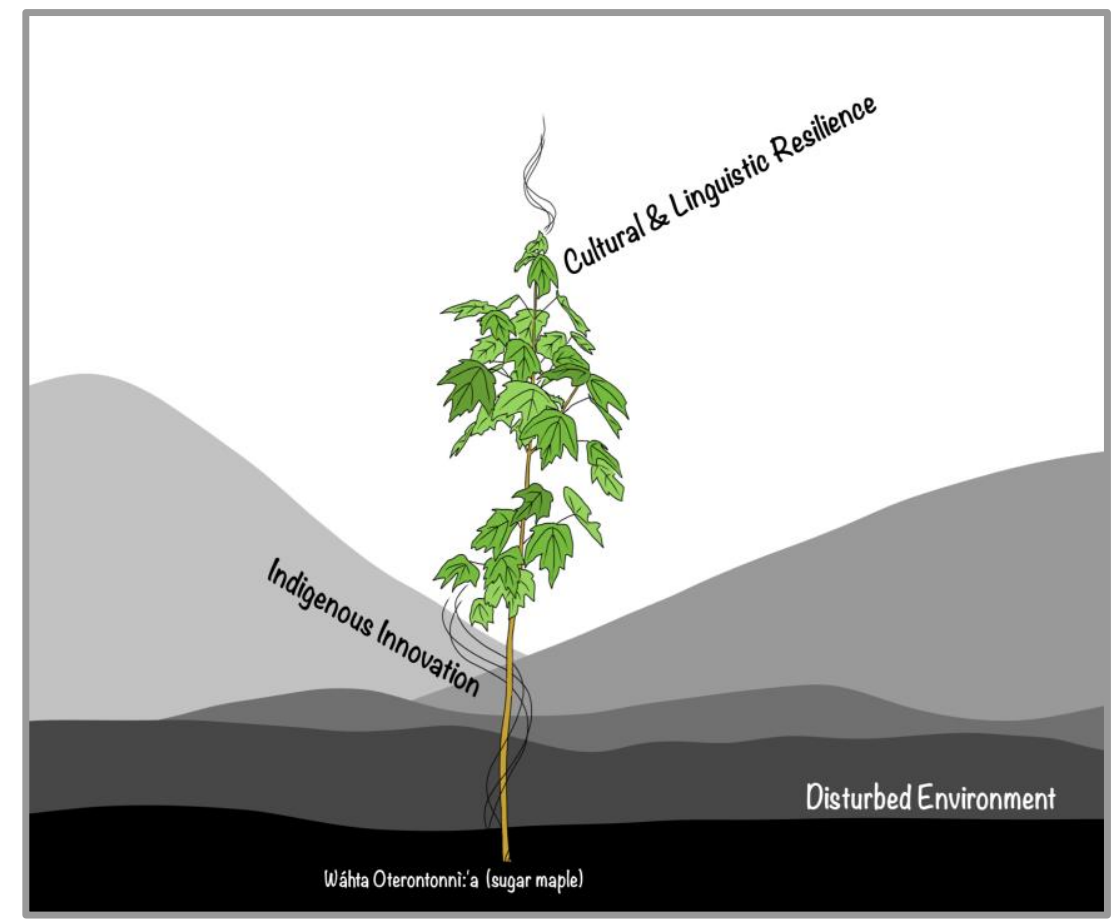

A survey of events and experiences from our past plays a critical role in shaping our thoughts and actions for the future. It is through this grounding of retrospection that Indigenous people, communities, and civilizations are able to deem what remains significant, essential, and influential to its culture while remaining resilient in modern times through adaptation and innovation. This dualistic relationship between change and maintenance of cultural knowledge raises the following essential question and the focus of this article: How does innovation ensure linguistic and cultural resilience for Indigenous people? 
As Indigenous cultural practitioners working within four respective fields: 1) Hawaiian translation and interpretation, 2) Hawaiian song and music, 3) Indigenous food sovereignty, and 4) Kanien'kéha (Mohawk language) documentation and revitalization, the researchers of this article are often confronted with the aforementioned question in the pursuit to ensure the revitalization, maintenance, normalization, and overall survival of Indigenous cultures within a world of ongoing pressures by colonial forces to assimilate into the dominant society.

This article will reveal the importance of Indigenous innovation for the resilience of Indigenous language and culture and will highlight the unavoidable truth—that cultures and languages must adapt with the changing of time to ensure survival. Through autoethnography and personal interviews with cultural practitioners working within the four aforementioned areas of practice, this article reports and highlights observations on how innovation is occurring within such practices. By creating an awareness of the possibility of innovation in these various fields, the outcomes will serve as outlets for future reference in the collective Indigenous pursuit to ensure the continuity of Indigenous languages and cultures.

\section{Literature Review}

Indigenous people have historically overcome profound adversity, namely what has been associated with colonial expansion and assimilation. Due to a certain resilience at individual, societal, and cultural levels, many Indigenous groups have been able to maintain their languages and cultures. Originating in psychology and later ecology, the term "resilience" generally refers to an entity's ability to overcome disturbances, namely external in origin 
(Kirmayer et al., 2011). This article specifically focuses on linguistic and cultural resilience and how Indigenous people are re-organizing, innovating, and adapting in order to maintain and transform their language and culture to suit modern times.

Walker and Salt (2006) define resilience as "the capacity of a system to absorb disturbance and still retain its basic function and structure" (p. xiii). Furthermore, as discussed by Kirmayer et al. (2011),

In biological systems, resilience usually does not involve simply springing back to a previous state but is a dynamic process of adjustment, adaptation, and transformation in response to challenges and demands. (p. 85)

This resilience is not about returning to a previously untouched or uninfluenced state. Rather, it is a dynamic process rooted in retrospection that allows a people, their language, and their culture to adjust and transform in response to external forces while changing the environment that surrounds them. By creating new habits, adapting to contemporary development, and maintaining an Indigenous attitude through practice, a culture becomes resilient.

In the context of this article, linguistic and cultural resilience is additionally inspired by and grounded in the ideas of "resilience thinking" (Walker \& Salt, 2006, p. 190), which, since the beginning of the $21^{\text {st }}$ century, has spread in use throughout a range of disciplines. As stated by Roche (2017), resilience thinking is 
A framework for analyzing complex systems that portrays sustainability as a dynamic rather than a static state, and places emphasis on adaptively responding to, rather than avoiding or resisting, disturbances to the system. (p. 190)

Rather than total assimilation without retainment of tradition, the most resilient of cultures embraced innovation and application of change as a way to complement their already genius existence.

The term "Indigenous innovation" has been discussed within many areas of study such as sociology (Walters \& Takamura, 2015), ecology (Roche, 2017), psychology (Roche, 2017), and anthropology (Charlot, 2005). For the purposes of this article, Indigenous innovation is summarized as innovation through retrospection, making informed decisions for the future based on the past. It is understood that the resilience exhibited by Indigenous people is embedded in long-held practices of Indigenous innovation that are linked and fundamentally tied to what has come and been practiced before. This acknowledgement of the past can be exercised and expressed in many measures by Indigenous people by building one's literacy of language and culture. Before Indigenous innovation can occur, an individual or group will need to understand the urgency of a loss within the culture. Upon recognizing this incident, action in a strategic, sensitive, and sustainable manner is formulated to provide such justification in backing its Native beginnings. e holistic discourse surrounding linguistic and cultural Indigenous innovations, this article provides a detailed analysis of how chosen individuals showcase the importance of change for the survival of their language, culture, tradition, and lifestyle. 


\section{Methodology: Autoethnography and Personal Interviews}

Autoethnography is "an approach to research and writing that seeks to describe and systematically analyze (graphy) personal experience (auto) in order to understand cultural experience (ethno)" (Ellis et al., 2011, p. 1). From the traditional Western academic view, personal narrative is often thought to lack objectivity, a concept deemed to be essential within evolving conventional academic discourses. Because of this, personal narrative is often viewed as a methodology that lacks accuracy and rigor. This is often the contrary within Indigenous paradigms that tend to blur the lines between the objective and the subjective and emphasize the critical importance of personal experience and personal context in coming to know and understand (Houston, 2007; Smith, 2013).

For the importance of congruent research methodologies, Indigenous researchers have the privilege of understanding subjectivities and perspectives from none other than their own cultural lenses (Chew et al., 2015). Therefore, from an Indigenous lens, autoethnography is an appropriate methodology for providing an authentic and representational voice of personal experience while simultaneously maintaining academic rigor (Houston, 2007).

For this article, autoethnography brings to light not only the connection between the researcher and their respective field of work, but also the relationship between the researcher and their fellow cultural practitioners. Because all researchers of this article are also practitioners within their respective fields of study, they have created long-lasting and personal relationships that far predate the writing of this article. From an Indigenous perspective, the importance of relationship is clear in the ideology that symbiotic 
relationship leads to the survival of all: The farmer shares his crops with the fisherman who shares his fish. Because of this, personal interviews were employed as a means to gain perspective on the importance of Indigenous innovation in the four various fields of study. These interviews were semi-structured, allowing the conversation to flow where necessary. The interviewees were given the following prompts:

1. Tell me about the Indigenous innovation in your field of work.

2. How has Indigenous innovation been beneficial in your field?

3. How does Indigenous innovation in your specific field ensure the resilience of language and culture?

4. What are some possible challenges and obstacles that arise from Indigenous innovation?

As we are Indigenous researchers and practitioners in various fields, it would be a folly to not pursue this research inclusively. It allows a resurgence of Indigenous thought and perspective reformatted to fit a modern time. It fosters the ideas of interconnectivity and interdependence in the sense where the "one" works for the "whole." It challenges the Western framework of what true methodology actually is: for the betterment of those studied, not for the potential gain of the researcher. It is for these reasons that this article portrays the research in this fashion.

\section{Autoethnography}

\section{Hawaiian Translation and Interpretation: Ian Nāhulu Maioho}

My name is Ian Nāhulu Maioho and I was born in Honolulu, O'ahu and raised on the rural island of Moloka'i. I am of Native Hawaiian descent, and I was immersed in Standard 
American English and Hawaiian Creole English at home while learning 'ōlelo Hawai'i (Hawaiian language) at school. Because of this multilingual upbringing, I was aware from a young age of the existence of a complex multilingual and multicultural world.

After graduating with my master's degree in Indigenous Language and Culture Education from the University of Hawai'i at Hilo in 2014, I began working in 2015 as a translator mentee at Awaiaulu Inc., an organization dedicated to making Hawaiian knowledge accessible through translation. There, I was mentored on translating and interpreting Hawaiian language material from the 19th and early 20th centuries for a contemporary 21st century audience. I learned how to bridge resources and knowledge from the past to a current audience through translation and interpretation. After 2 years, I became a mentor as I took two mentees under my wing to become Awaiaulu translators themselves.

Through my work at Awaiaulu, I have made lifelong connections with fellow Native Hawaiian translators spanning the Hawaiian archipelago and beyond. The three individuals whom I interviewed for this article are seasoned translators and are currently employed at Awaiaulu Inc. They represent different "generations" of Awaiaulu Inc. totaling a sum of over 15 years of experience there. Kalei Kawa'a was a mentor of mine who has been at Awaiaulu for more than 7 years; another interviewee, Ha'alilio Solomon, a fellow mentee, has been at Awaiaulu for 5 years; and another interviewee, Aolani Ka'ilihou, a mentee of mine, has been at Awaiaulu for 3 years. 


\section{Innovation in Hawaiian Song and Music: Nicholas Keali'i Lum}

Music, in the most general sense, has been a foundational aspect of my life that continues to shape and mold my character, my direction, and my consciousness. I come from a musical family and was raised, with my older brother, by two loving parents in Ha'ikū, He'eia on the eastern side of $\mathrm{O}^{\prime}$ ahu. I fondly remember music being a constant throughout my childhood, whether it was listening to Hawaiian music on the radio or strumming the 'ukulele at our weekly family gatherings. This early nurturing of my love for Hawaiian music set the stage for a lifelong commitment to ensuring the resilience of not only Hawaiian music, but Hawaiian language and culture in totality.

After my graduation from the Kamehameha Schools Kapālama, I furthered my education at the University of Hawai'i at Mānoa obtaining a Bachelor of Arts degree in Hawaiian as well as a Bachelor of Arts degree in music. I then continued on to higher level education and obtained a Master of Arts degree in Hawaiian. It was during this time that as "Keauhou," we began to record and release studio albums. Three albums were released in 3 consecutive years and garnered a total of 17 Nā Hōkū Hanohano awards, the Hawaiian equivalent of the American Grammy.

I have conducted two interviews with famed and innovative Hawaiian artists from different generations, Robert Uluwehionāpuaikawēkiuokalani Cazimero and Kainani Kahaunaele. During my college years, I became an 'ōlapa (hula practitioner) of Hālau Nā Kamalei o Lìlīlehua under the direction Cazimero, a multi-award-winning musician, haku mele (song writer) and kumu hula (hula teacher). Coming from high musical prestige with "The Brothers 
Cazimero" as well as "The Sunday Mānoa," Cazimero illustrates a constant reminder of where we have been (specifically during the Hawaiian Renaissance and the Indigenous innovation found there), where we are now, and where we must go as practitioners of mele Hawai'i to ensure its resilience.

It was also during these years that I fostered many personal relationships with my fellow practitioners of Hawaiian song, one of whom is Kainani Kahaunaele, a multi-award-winning musician, haku mele, and teacher at Ka Haka 'Ula o Ke'elikōlani, College of Hawaiian Language at the University of Hawai'i at Hilo. She is known for her innovative style of Hawaiian music that is grounded in Hawaiian thought and perspective.

\section{Indigenous Food Sovereignty: Naupaka Damienne Joaquin}

Born into a genealogical lineage of Portuguese, Filipino, and Hawaiian ancestry, I recall my childhood being a culturally diverse one. Growing up in small town areas on the island of Maui, I, along with my siblings and cousins, were cared for dearly by our grandmother, Louisa Kaaihue Artates, in our early childhood days into adulthood. Widowed with a fixed income, my grandmother was always able to be hospitable to all who came to visit. The first few words of her greeting never fail to persist, "You bettah go eat!"

It was after adolescence and my years of formal institutionalized education that I came to appreciate and research the idea of feeding. How did this proverb of my childhood, "You bettah go eat," seem so simple, but yet was rooted in an Indigenous way of thinking? This path of discovery and understanding the importance of feeding came years after I learned 
and applied a Hawaiian epistemology to my urbanized lifestyle. Once fluent in the language, I saw that my changes in behavior, values, and choice were backed by my literacy in stories, myths, legends, and accounts that suggest, within its history, the significance of study.

It also became evident to me as a mother of a young, active family, that the high costs of living on an island that once relied wholly upon sustainable resources was now difficult due to colonial oppressions. It was through my work as a Hawaiian medium educator where I was able to work among professionals of all sorts that I began to pursue a couple of individuals who were brought into families/communities where eating was the means of survival.

I have chosen two individuals who are deemed to be experts in the philosophy of sustainable gathering and farming to highlight important perspectives of an Indigenous food sovereignty lifestyle. These individuals will serve as specialists in their respective fields and can be retrieved to further expand upon areas of question or inquiry. Ali'i Robin Hauani'o is the son of two papaya farmers from Pāhoa, Hawai'i who shares his insight as to how education influences students, particularly in the ways of farming and using tools and how work ethics are introduced through performance. Hauani'o has a unique attitude, cultural understanding, and linguistic background that best exemplifies what and how ancient farmers may have practiced. Tetauavavaopu Teikitekahioho, a noble home farmer, is another participant originally from Nukuhiva, French Polynesia. As an educator, I have had the privilege of meeting with Teikitekahioho for a number of years. She has witnessed my growth as a mother to my son and shares the commonalities of Indigenous lifestyles that are important to instill within our children while practicing familial traditions. 


\section{Kanien'kéha Documentation for Revitalization: Ryan DeCaire}

Among the many areas in which language revitalization work takes place in Indigenous communities, documentation is especially important for any opportunity at language revitalization. I learned this principally through my experience growing up and working in Wáhta Mohawk Territory, a small Kanien'kehá:ka (Mohawk) community in Ontario, Canada with very limited Kanien'kéha (Mohawk language) vitality.

I have become intimately involved and focused on documenting the language vitality situation in Wáhta and other Kanien'kehá:ka communities. The completion of the first ever language revitalization plan in Wáhta led me to become formally involved in developing and completing the first language documentation project ever in Wáhta. This project was an oral history language documentation project called Tewanónhstat ne Rotiksten'okòn:'a Raotiwén:na "Preserving the Voices of Our Elders" (Wáhta Mohawks, 2019). The final product is a 3-hour video in a documentary format where highly proficient and semi-speaker first-language speakers talk about Wáhta history, changes in the Wáhta culture and community over time, and the importance of language to community and Kanien'kehá:ka identity and well-being.

From my experience in documentation work in Wáhta, I have come to understand the importance of being innovative to acquire a more robust account of how the language is actually used on an everyday basis in Kanien'kehá:ka communities. This can be done, for example, by focusing more on "learner-directed speech," which allows us to capture more authentic language, such as language functions, idiomatic expressions, metaphors, and 
conversations concerning the everyday lives of our speech community (Amery, 2009; Sugita, 2007), ultimately producing something that will be useful to language revitalization in the Kanien'kehá:ka community today and in the future. I have learned this in part from my own experience, but also from sharing with other Kanien'kehá:ka language practitioners engaged in documentation work, including Tahohtharátye Joe Brant and Nicole Bilodeau, whom I interviewed for this article.

\section{Findings}

Across all four fields of study-Indigenous innovation in Hawaiian translation and interpretation, Hawaiian song and music, Indigenous food sovereignty, and Kanien'kéha documentation - a total of nine cultural practitioners were interviewed. They served as representatives for their individual fields to explain their perspectives on the importance of Indigenous innovation for the resilience of language and culture. Included below in Table 1 are the names of those interviewed separated by cultural practice.

\section{Table 1}

Indigenous Innovators and Expert Areas

\begin{tabular}{|l|l|l|l|}
\hline $\begin{array}{c}\text { Hawaiian } \\
\text { Translation and } \\
\text { Interpretation }\end{array}$ & $\begin{array}{c}\text { Hawaiian Song and } \\
\text { Music }\end{array}$ & $\begin{array}{c}\text { Indigenous Food } \\
\text { Sovereignty }\end{array}$ & \multicolumn{1}{|c|}{$\begin{array}{c}\text { Kanien'kéha } \\
\text { Documentation }\end{array}$} \\
\hline Aolani Ka'ilihou & Robert Cazimero & Ali'i Hauani'o & Nicole Bilodeau \\
\hline Kalei Roberts & Kainani Kahaunaele & $\begin{array}{l}\text { Tetauavavaopu } \\
\text { Teikitekahioho }\end{array}$ & $\begin{array}{l}\text { Tahohtarátye Joe } \\
\text { Brant }\end{array}$ \\
\cline { 1 - 3 } Ha'alilio Solomon & & \\
\hline
\end{tabular}


Upon completion of the interviews, each individual researcher transcribed their interviews and culled the main topic quotes from each. These quotes were then analyzed collectively and sorted into four main themes that each interviewee highly stressed during their interview. The themes are shown in Figure 3. Through strict analysis, these themes support how Indigenous innovation ensures the resilience of language and culture.

\section{Figure 3}

Theme Sequence of Analysis Outcomes

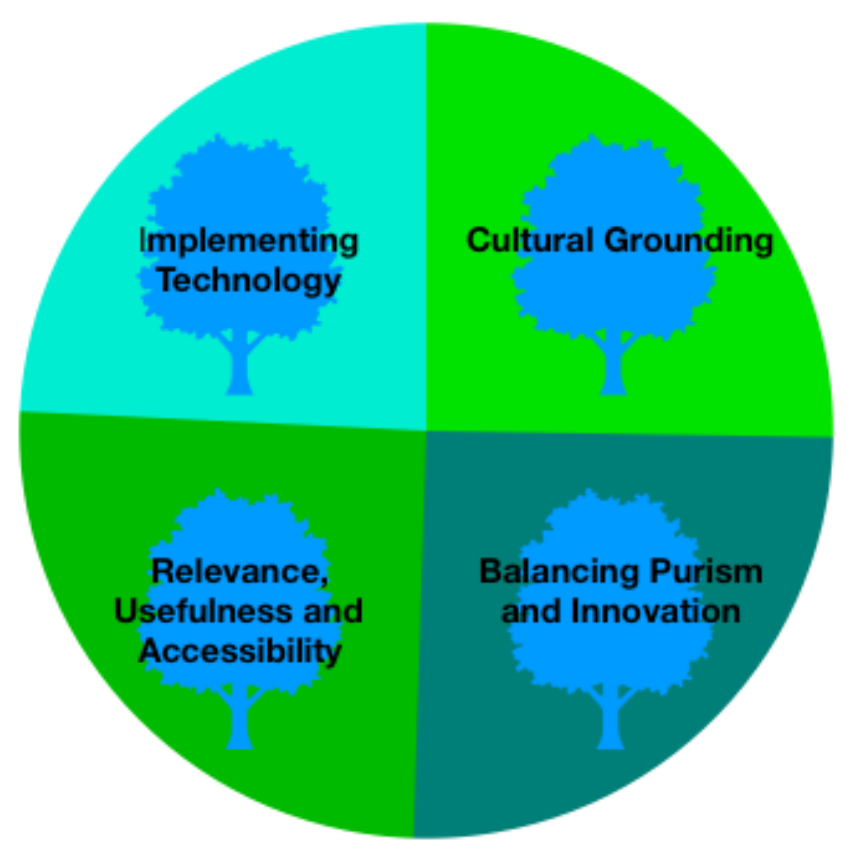

\section{Technology}

The first topic to be discussed is the Indigenous implementation of foreign technology. Technology is "the application of scientific knowledge to the practical aims of human life or, as it is sometimes phrased, to the change and manipulation of the human environment" (Encyclopaedia Britannica, n.d.). Being something that applies knowledge to the practicality 
of human life for the purpose of changing, technology was not surprisingly a common topic discussed by several of the interviewees in regard to Indigenous innovation. The research has found that a form of Indigenous innovation is the implementation of foreign technology by and for Indigenous people to assist in their linguistic and cultural resilience. Areas that foreign technology has been adopted and adapted by and for Indigenous peoples are technologies aiding in food production, in recording and documentation, in keeping the purity of literature, and in creating platforms for collaborative work.

When talking about food production, "Hawai'i is so ahead," said Teikitekahioho, an Indigenous woman of Nukuhiva, Marquesas Islands, French Polynesia, upon reminiscing about her first observations of Indigenous innovation in Hawai'i. Teikitekahioho mentioned that technology made things fast and easy. Hauani'o shared that modern tools now used in Hawai'i are a step up from traditional Native Hawaiian tools and his experience in modern farming and agriculture helped him apply modern technology such as shovels, pickaxes, and rotary-tillers to help him become the successful Indigenous farmer he is today. He, however, adds that the 'o'ō (traditional Hawaiian digging spade) is still necessary for his practice in contemporary times. Hauani'o shares the reasons why technology was and continues to be useful:

It wasn't too hard to incorporate those tools and machinery, being that the machinery would help to multiply one individual's efforts. Where, as opposed, maybe would need to have 3-4 people to do the job, we're [utilizing] our equipment back here, one person can do [the job].... When it was just me and 'Anakala Isaiah, [it] was just the two of us, so the machine [was] a big help.... Then [when educating] our students, we always 
try to make the effort to tie the past with the modern and just remind them that these tools [are what is] available to us now.

One important historical instance of Western technology that was made available and utilized by Native Hawaiians was writing orthography when it was first introduced to the Kingdom of Hawai'i by Calvanist missionaries in the 1820s. During those early years of learning literacy in Hawai'i, the Native Hawaiian king at the time, King Kauikeaouli Kamehameha III, proclaimed that his kingdom was one of literacy and thus Native Hawaiians adopted the technology of reading and writing as being a symbol of the kingdom, and, therefore, a large part of their Native Hawaiian identity (Kamakau, 1868). This adoption of literacy translated to decades of innovation of this technology as a means of not just teaching and learning the Gospel, but also recording Native Hawaiian literature and communicating cultural practices with nationwide Native Hawaiian audiences (Nogelmeier, 2003). Today, technologies such as tape recorders and video cameras assist in this custom of recording Native Hawaiian knowledge and disseminating it to the larger Indigenous community. Brant, a Kanien'kéha documentation practitioner in Canada, explained, "we use 'colonial instruments' that are most efficient. We need to use the practical and efficient pieces of technology that we can in order to get this done." Brant also added that "audio/video is also important to help in understanding the more pragmatic aspects of speaking the language such as gesturing or posturing." Bilodeau, another Kanien'kéha documentation practitioner in Canada, shared that many recordings of Indigenous language Native speakers have been audio recorded and were not disseminated or formatted in ways that are physically accessible to the larger Indigenous community. Bilodeau shared how audio/video recordings 
help to innovate traditional Indigenous storytelling into a new platform that is easily disseminated and made accessible to the larger Indigenous community:

I think that our approach was kind of like a documentary approach rather than just collecting interviews. It was more of an approach that you would see if you were watching a documentary on any modern topic. I think that was kind of innovative, that we were using this format for storytelling that we haven't seen that much of in relation to language.

In the space of translation and interpretation, many Native Hawaiian scholars and educators have been summoned to become translators and interpreters due to the growth of language usage among younger generations (Wang, 2018). One of these translators, Solomon, shares how he is able to apply linguistic knowledge in his practice of language translation: "Innovation I would say I participate in is through applying linguistic knowledge that I have gained through my graduate program to help offer alternative explanations, descriptions, or pedagogies about 'ōlelo Hawai'i to other learners and speakers." Many of these young translators are learning the art of translation on virtual platforms and collaborating in translation work via these same platforms. One organization that is pioneering this innovative approach to building the capacity of Hawaiian language translators is Awaiaulu Inc. One of Awaiaulu's key personnel, Roberts, shared,

Technological advances that we have today, [allow for] our Awaiaulu personnel [to] have spanned the state of Hawai'i and even Aotearoa. Technology and its tools have allowed for that, where in the past, we were limited to meetings and projects strictly operating out of $\mathrm{O}^{\prime}$ ahu. Though $\mathrm{O}^{\prime} \mathrm{ahu}$ still serves as the main headquarters, we are 
able to work online through various applications and software from Skype to Google Suite etc. It's allowed for us to grow and expand like we never imagined.

\section{Relevance, Usefulness, and Accessibility}

The need for language and culture to be relevant, useful, and accessible to current and future generations of all ages was a theme shared among our interviewees. Almost all interview respondents stressed that innovation in their respective fields is necessary for culture and language to remain relevant and useful and, therefore, accessible to the present lives of their Indigenous communities. This mirrors what is said in the literature as well as what was experienced by the researchers within their work as Indigenous practitioners.

The idea that if our own people, with special attention towards children and future generations, are going to play a role in maintaining linguistic and cultural resilience, they need to understand their language and their culture as being relevant and useful within their everyday lives despite modern world changes. This points to the notion that language and culture are not solely suited for ceremonial or ancestral domains, which modernization in Indigenous communities can often suggest, and that language and culture must be commonplace, usual, and, of course, be accessible to people with different knowledge and experiences. This is especially important for younger generations who often face societal pressures to "fit in," leading them to adopt dominant cultural norms.

Brant speaks directly to this when talking about how language documentation needs to consider the lives of present and future language learners, most of whom are and will be 
second-language learners with very different life experiences from first-language elder speakers of Kanien'kéha: "We need to bring it [the language] into their lives. Learning has to be applicable to their lives. They have to see it as an everyday occurrence. As a contemporary and relevant activity." Brant is speaking to the idea that although all language documentation could be useful to a speech community in some way or another, most historical and present documentation of Indigenous languages has often not focused on capturing language that new generations of speakers will be compelled to use or need to use on an everyday basis. He adds that language documentation and pedagogical materials developed from such documentation must "concentrate on things that affect language learners every day" and that "it has a practical application that is going to affect language proficiency." This points to the idea that context really matters and that for a language and culture to remain resilient, its speakers must allow it to adapt and adjust with changing societal norms so that it remains relevant and, therefore, useful and accessible to the speech community. Bilodeau, another practitioner who has worked in language documentation, puts special attention towards this when she states that "we need to think about what will be useful to people beyond just documenting it and storing it somewhere," and that "you have to keep the context in mind so that you're creating resources that are useful and are in line with wherever you're at in your language vitality as a community."

If Indigenous language and culture are going to be resilient in the face of pressures to adopt the dominant global culture, innovation must take place that allows the language and culture to remain relevant by adopting aspects of dominant culture while being informed by linguistic and cultural knowledge and traditions. Hawaiian musician, Kahaunaele, talks about 
the need for bridging classic Hawaiian music with more popular forms of music as a means to increase exposure and accessibility to Hawaiian music and make it more relatable and "consumable" to listeners:

One of the most prevalent benefits would be to encourage the young people of today, or even our community, to expose our classic mele in the styles that the general community consumes. And unfortunately, Hawaiian music, as we call it, isn't as popular, or isn't as integrated into every household as we would like it to be. Because, as musicians, we love all kinds of music as well, and it's a natural progression, natural evolution, to bring our poetry into the music styles that we love.

Contrary to many conservative ideologies that argue for language and culture to remain in their "purest" form, untouched by dominant society, this suggests that innovation is, in part, defined by bringing together aspects of Indigenous and non-Indigenous culture and language and that doing so makes it more relevant and accessible to present day Indigenous people. This, as a result, leads to greater linguistic and cultural resilience. Roberts, regarding the role of innovation in translation and interpretation, points directly to this when she states that "if Hawaiians are innovating, then they are engaging deeply and meaningfully in knowledge sets that originate across time while finding useful, functional, perhaps crucial current relevance. This is what I believe responsible, true innovation aims at." This touches on the related theme identified in our research, that relevance is in many ways dependent on maintaining a balance between being informed by long-held Indigenous knowledge and traditions and also changes in modern society. Ka'ilihou, regarding the mission of the organization Awaiaulu Inc. and the role of translation and interpretation within that organization, points to this and how 
it is necessary in ensuring that linguistic and cultural content are relevant and accessible to Indigenous people with different degrees of linguistic and cultural knowledge and experience:

Its [Awaiaulu's] translation services aim to bridge a gap that exists between the haves and the have-nots. The projects that are produced are not standalone translations, but instead, a supplemental text to assist both Hawaiian language speakers and nonspeakers alike in interpreting the text. These supplemental translations provide a gateway for those who are interested in learning the language to "dip their toes," so to speak, in the material that they could have access to if they are in fact interested.

Ultimately, this highlights that, as human beings, we are in constant change and flux. If Indigenous languages and cultures are to become and remain resilient, it needs to be understood that lives and experiences change, that environments change actions, and that actions change environments. This has a constant impact on what is useful and relevant to the lives of Indigenous people. Brant makes this clear when he states that "the focus [of language documentation and revitalization] is going to change every single year," so that it can cater to what is relevant and needed by the Indigenous community.

\section{Cultural Grounding}

Innovation can be a controversial topic when ethics, design, and cultural traditions are altered. This alteration of culture, which expands to language, behavior, occupation, and even arts, can be illustrated as a means of resilience. Preservation through practice is expected in order to be responsible and accountable for modifying any feature of culture. 
A recurring theme that the interviewed practitioners found impactful and necessary for resiliency in their area of work (translation, song, Indigenous food sovereignty, and language documentation) is that of cultural grounding. Kahaunaele, artist of contemporary Hawaiian music and second-language speaker, shared two significant terms that may possibly lead to a standard of measuring Indigenous innovation: prerequisite and delivery.

The prerequisite would be to be a practitioner of Hawaiian music, not just to know about the music, but to know about the delivery of it. And to know that there are poetic standards. There are levels to haku mele (song writing). We all began at ground zero; it takes years of practice and passion to become better.

Attaining prior Indigenous knowledge as a prerequisite to practice, innovate, and perpetuate has been highlighted here as a fundamental feature of responsible innovation. The delivery, or transmission, of knowledge through teaching and creating also serves as a significant detail in change and modification of cultural practices. Delivery in relation to innovation supports the standards of cultural grounding that encompasses not only the relationship of people but also the environment or space.

Adding to the standards of cultural grounding, literacy becomes apparent to the innovator in reclaiming and defending their tradition. The capacity of knowledge that such an expert acquires originates from Indigenous resources: genealogies, stories, legends, first-hand accounts, and later outside references that complement or build upon understanding. Further learning and research is expected to gain sufficient knowledge in any area of study. When comprehension occurs, expansion of knowing takes place. Hawaiian translation specialist, Roberts, brings attention to the power of imagery in her scope of work and how 
this allows for interpretation by those who have limited knowledge or are at the beginning stage of understanding how to be innovative:

For example, there are times in which, as translators, our knowledge of what we are translating is limited. This can occur for many reasons, but often because we are not familiar with the practice that has been documented. Our own images, as translators, highly influence how we translate those sections.

Roberts, along with her fellow translators at Awaiaulu Inc., recognize the amount of reference needed to accurately define and transcribe some of Hawai'i's most endearing historical accounts.

To possess special skill and knowledge or be trained by practice are both characteristics of an expert. The excellence in practice of the individual does not occur immediately. Observation, listening, silence, and imitation are a part of an Indigenous learning process. From the previous and upcoming informants that were acknowledged and interviewed, many promoted the idea of continuity through learning. Whether generational, institutional, or formal, education has many constructs that have similar goals in producing a fine apprentice. Throughout many traditional features of culture-language, occupation, or arts-its very survival is highly associated with innovation and change. Teikitekahioho reminisces about the time spent accompanying her fisherman father who spoke, acted, and lived in a sustainable and resourceful way: "My dad was teaching me, grow your own food for your own family. I like to eat the fish from the ocean. I know I can get food from the ocean. That is how I wanted to teach my son. I wanted to feed like how my makua (parent) was teaching us." Moving to Hawai'i from French Polynesia, Teikitekahioho maintained her 
training practices of providing for her family in an Indigenous manner to the best of her ability. Innovations such as tools, machinery, and markets were all advantages to her already established praxis of knowing. If the circumstance is appropriate, the continuity of culture will be shared amongst those who will respectably perpetuate practice by responsible innovation.

\section{Balancing Purism and Innovation}

This final and heavily discussed topic deals with the balance between purism and innovation. The consensus between interviewees is that the vital importance of this balance exists in the middle of these opposite extremes. Just as a scale balance operates, there must be equal parts at each end to maintain harmony. The same holds true with the balance of traditional knowledge and innovation. When the overwhelming focus is placed on one or the other, the scale topples.

Cazimero speaks of this balance found within the two iconic and innovative Hawaiian music groups of which he was a part:

When Roland [Cazimero] and I went into being "The Brothers," Roland was the one who was more innovative in a style that was not necessarily Hawaiian, and so my job, and even with "The Sunday Mānoa," I felt that my job was to bring the Hawaiian part to it so that we always made sure that we had a solid foundation, a base, because I think that's really important.

This "base," of which Cazimero speaks, is the grounding in culture discussed previously. Innovation relies on a previous grounding and foundation of cultural knowledge in order to 
birth a new iteration of itself for modern consumption. This further reveals the symbiotic relationship between old and new and raises another caveat for its balance: Indigenous innovation is a spawn of traditional knowledge, not a separate entity lacking genealogical connection.

Challenging this balance are those who exist solely at the polar opposite ends. On the topic of Kanien'kéha, Brant states that "the purism approach and ultra conservative approach is very likely what is leading the language to its extinction." If one holds all value in what came before with no thought of the future, that of old vanishes into antiquity. If one holds all value in the creation of new, that of old becomes forgotten. Solomon describes this struggle in his practice of Hawaiian translation and interpretation:

I notice one of the tensions in the revitalization movement of 'ōlelo Hawai'i is the coining of new terms. This is certainly addressed and complicated in the field of translation theory, and the spectrum between "keep it traditional" and "invent anew" can be quite literally applied to the different institutions that teach 'ōlelo Hawai'i today. These differing philosophies create massive obstacles and discrepancies in the long- and short-term goals for each institution and begin to erode the unity of the movement.

The only path that allows true coexistence is found in the integration of both old and new at equal parts and value. Perhaps that is the true meaning of a living culture-a culture that is so firmly rooted that innovation is welcomed with open arms. 
But how does one successfully integrate innovation with tradition? As mentioned previously, a solid grounding in culture is mandatory before innovating. Brant raises a strong example of this in terms of Kanien'kéha: "It is important for second-language learners to have a high proficiency before you create with the language. You need to have the proficiency and Kanien'kéha way of knowing before you start messing with the language." Furthermore, approval should be granted by respected individuals of the practice before innovation begins. Kahaunaele speaks of this in her Hawaiian song writing process:

As a composer myself, I always think, "What would Larry [Kimura] think?" "What would Hiapo [Perreira] think?" "What would Kauanoe [Kamanā] think?" "What would Kalena [Silva] think?" People who practice chant and hula where we see innovation there all the time.

This approval not only provides backing for the innovator, but also reassurance that the new creation is that of the culture, not of foreign origin or desire.

Balance is a concept that traverses many boundaries and, in all situations, provides harmony and stability. The same holds true for the resilience of language and culture through Indigenous innovation. Ultimately, this is about survival, perpetuating our practices, philosophies, and ways of life to maintain our distinction as Indigenous people. Bilodeau frames this idea with truth and conviction: "Adapt or die. At this point, it's about survival. Maybe not for all Indigenous communities, but for us, it is. Survival, as in continuing to live and to exist as distinct people—those, to me, are the same." 


\section{Conclusion and Implications}

Through autoethnography and personal interviews within four specific fields-Hawaiian translation and interpretation, Hawaiian song and music, Indigenous food sovereignty, and Kanien'kéha documentation-this article highlights the importance of Indigenous innovation for linguistic and cultural resilience. The hope is that this article may serve as a reference for appropriate Indigenous innovation as well as become a driving advocate for innovation in Native cultures and languages abroad to ensure their survival. Like the durable 'a'ali'i shrub or the wáhta oterontonnì:'a that adapt in extreme habitats and ecosystems, Indigenous people too continue to exist throughout the world, persisting and advancing in foreign social environments. By remaining rooted in a medium that grounds Indigenous communities and extending their reach to allow space for creativity amidst winds of change, Indigenous languages and cultures will continue to blossom and produce saplings that will carry forth new generations of hope and continuity.

It is our hope not only as the writers of this article, but also as Indigenous people, that more of our future actions will take a leap into responsible innovation by acknowledging its features of longevity, relevance, and prosperity to ensure the resilience of our Indigenous languages and cultures. Let us continue to let nature be our guide, allowing for adaptation and creation, so that we may continue to exercise autonomy over our own destinies. 


\section{Glossary}

'A'ali'i

Awaiaulu Inc.

Haku mele

Haudenosaunee

Kanien'kéha

Kanien'kehá:ka

Kumu Hula

Mele Hawai'i

‘Ōlapa

'Ōlelo Hawai'i

'Ōlelo No'eau

'0̄'ō

Shawíhskara

Tharonhiawá:kon

'Ukulele

Wáhta

Wáhta oterontonnì:'a
Shrub growing abundantly throughout the Hawaiian island chain

An organization dedicated to making Hawaiian knowledge accessible through translation

Song writer

The Iroquois people

Mohawk language and culture

The Mohawk people

Hula teacher

Hawaiian song

Hula practitioner

Hawaiian language

Hawaiian proverb

Digging stick

"Flint"-One of the male twins in the Haudenosaunee creation story

"He Holds the Sky"-One of the male twins in the Haudenosaunee

creation story

Musical instrument of four strings

Sugar maple tree (Mohawk)

(sugar maple sapling) native to the Haudenosaunee territory in the north-eastern woodlands of North America 


\section{About the Authors}

All four authors are doctoral candidates in the Hawaiian and Indigenous Language and Culture Revitalization program at the University of Hawai'i at Hilo, Ka Haka 'Ula o Ke'elikōlani College of Hawaiian Language.

Ryan DeCaire is Kanien'kehá:ka (Mohawk) and was born and raised in Wáhta Mohawk Territory, Ontario, Canada. He is an assistant professor in the Department of Linguistics and Centre for Indigenous Studies at the University of Toronto, and a curriculum developer at Onkwawén:na Kentyóhkwa, an adult Kanien'kéha (Mohawk language) immersion school.

Naupaka Damienne Joaquin is the daughter of Warren Gouveia of Hāli'imaile, Maui and Lourdes Gouveia of Keokea, Maui. Joaquin is an educator in Hawaiian medium education and lives a novice lifestyle raising poultry and producing wild boar sausage along with her family in Puna Hawai'i.

Nicholas Keali'i Lum is a kupa of Ha 'ikū, O'ahu. He works at the University of Hawai'i at Mānoa with the Kaiapuni Assessment for Educational Outcomes team (KĀ'EO), aiding in assessment development for Hawaiian immersion schools. He is also a member of the multi-award winning traditional Hawaiian music group "Keauhou."

Ian Nāhulu Maioho is a keiki of Moloka'i Nui a Hina and works for Kamehameha Schools. He was recently a translator and mentor at Awaiaulu Inc. where he helped to translate hundreds of Hawaiian language newspaper articles to increase public accessibility and for future printing. 


\section{References}

Amery, R. (2009). Phoenix or relic? Documentation of languages with revitalization in mind. Language Documentation \& Conservation, 3(2), 138-148.

http://hdl.handle.net/10125/4436

Charlot, J. (2005). Approaches to the academic study of Hawaiian literature and culture. The Pacific Institute.

Chew, K. A. B., Greendeer, N. H., \& Keliiaa, C. (2015). Claiming space: An autoethnographic study of Indigenous graduate students engaged in language reclamation. International Journal of Multicultural Education, 17(2), 73-91. http://doi.org/10.18251/ijme.v17i2.966

Gilman, E. F., \& Watson, D. G. (1993). Acer saccharum: Sugar maple. Forest Service Department of Agriculture. http://hort.ufl.edu/trees/ACESACD.pdf

Ellis, C., Adams, T., \& Bochner, A. (2010). Autoethnography: An overview. Forum Qualitative Sozialforschung/Forum: Qualitative Social Research, 12(1), 273-290. http://doi.org/10.17169/fqs-12.1.1589

Encyclopaedia Britannica. (n.d.). Technology. in Encyclopaedia Britannica. Retrieved October 2019, from https://www.britannica.com/technology/technology

Hewitt, J. N. B. (1903). Iroquoian cosmology. Twenty-first annual report of the Bureau of American Ethnology, 1899-1890.

Houston, J. (2007). Indigenous autoethnography: Formulating our knowledge, our way. The Australian Journal of Indigenous Education, 36(S1), 45-50. http://doi.org/10.1017/S1326011100004695

Kamakau, S. M. (1868). Ka Moolelo O Na Kamehameha - No ka Noho alii ana o Kauikeaouli ma luna o ke Aupuni, a ua Kapa ia o Kamehameha III. Kuokoa, p. 1.

Kirmayer, L. J., Dandeneau, S., Marshall, E., Phillips, M. K., \& Williamson, K. J. (2011). Rethinking resilience from Indigenous perspectives. The Canadian Journal of Psychiatry, 56(2), 84-91. https://doi.org/10.1177/070674371105600203

La Via Campesina. (2020). The international peasant's voice. La via campesina: International peasant movement. https://viacampesina.org/en/international-peasants-voice/

Native Plants Hawai'i. (2009). Dodonaea viscosa. http://nativeplants.hawaii.edu/plant/view/Dodonaea viscosa 
Nogelmeier, M. P. (2003). Mai pa'a i ka leo: Historical voice in Hawaiian primary materials, looking forward and listening back [Doctoral dissertation, University of Hawaii at Manoa].

Payette, S., Frégeau, M., Couillard, P. L., Pilon, V., \& Laflamme, J. (2018). Sugar maple (Acer saccharum) at its northeastern range limit: A fire-resilient tree species. Botany, 96(6), 411-423. https://doi.org/10.1139/cjb-2018-0016

Pukui, M. K. (1983). Ōlelo no'eau: Hawaiian proverbs \& poetical sayings. Bishop Museum Press.

Roche, G. (2017). Linguistic vitality, endangerment and resilience. Language Documentation and Conservation, 11, 190-223. http://hdl.handle.net/10125/24733

Smith, L. T. (2012). Decolonizing methodologies: Research and Indigenous peoples. Zed Books Ltd.

Sugita, Y. (2007). Language revitalization or language fossilization? Some suggestions for language documentation from the viewpoint of interactional linguistics. In Proceedings of first conference on language documentation and linguistic theory (pp. 243-250). School of Oriental and African Studies (SOAS), University of London.

Wáhta Mohawks. (2019). Tewanónhstat ne rotiksten'okòn:'a raotiwén:na/Preserving the voice of our language keepers. Wáhta Mohawk Territory: Wáhta Mohawks.

Walker, B., \& Salt, D. (2012). Resilience thinking: Sustaining ecosystems and people in a changing world. Island Press.

Walters, F., \& Takamura, J. (2015). The decolonized quadruple bottom line: A framework for developing Indigenous innovation. Wicazo sa review, 30(2), 77-99. http://doi.org/10.5749/wicazosareview.30.2.0077

Wang, F. K-H. (2018, February). Hawaiian language finds new prominence in Hawaii's courts decades after near disappearance. NBC News. https://www.nbcnews.com/news/asian-america/hawaiian-language-finds-newprominence-hawaii-s-courts-decades-after-n851536 